\title{
Reinforced Subgrades with Fiber-reinforced Polymer Supporting Individual Footing
}

\author{
Chongxi Bai ${ }^{1,2}$, Lihui Qin ${ }^{1, *}$ and Xinyan Shao ${ }^{1}$ \\ ${ }^{1}$ School of Water Conservancy \& Civil Engineering, Northeast Agricultural University, Harbin, Heilongjiang 150030, China \\ ${ }^{2}$ School of Civil and Environmental Engineering, Nanyang Technological University, Singapore 639798, Singapore
}

Received 1 December 2017; Accepted 14 May 2018

\begin{abstract}
Fiber-reinforced polymer (FRP) materials are suitable as reinforcement owing to their excellent properties. To reveal the reinforcement mechanisms and effectiveness of FRP materials, a model was proposed for testing the mechanical properties of FRP-reinforced subgrade supporting individual footing. A non-reinforced case and eight reinforced cases were designed with variables such as the arrangement style and number of reinforcements. The soil failure patterns in the nine test cases were observed, settling of ground and reinforcement strains were tested, and the variations of ground settlement and reinforcement strain with footing pressure were obtained. The reinforcement mechanisms and effectiveness were determined by comparative analysis. Results show that the ultimate bearing capacity of subgrade increases by $450 \%$ and the ultimate settling of ground decreases by $41 \%$ for the case ch (subgrade horizontally reinforced with double plates) compared with the case an (subgrade without reinforcement). As for the case jv (vertically reinforced subgrade) with longer and higher vertical reinforcements, the ultimate bearing capacity of subgrade increases by $261 \%$, whereas the ultimate ground settlement decreases only by $4 \%$. This study can provide a reasonal arranging for the layout and number of reinforcements to attain a favorable reinforcing effect.
\end{abstract}

Keywords: Individual footing; FRP reinforcement; bearing capacity; settlement

\section{Introduction}

The majority of foundations of engineering structures are soft soil layers, which are unsuitable for the construction of shallow foundations on natural grounds, where the artificial grounds, pile foundations, or deep foundations are optional. Reinforced subgrades, as a type of artificial grounds, attain ground treatment by laying certain reinforcing materials in the foundation soil. Reinforced subgrades possess the advantages of land conservation, economic efficiency, technological advancement, local material utilization, and construction efficiency. Despite the reflection of the fundamental theories of reinforced subgrades in the existing codes, the reinforcement mechanisms for the individual footings supporting large numbers of wide range frame columns are unclear. Thus, certain shortcomings remain in guiding the design and construction. Meanwhile, novel reinforcing materials and rational arrangement modes should be explored to address the durability problem of reinforcing materials and the limited effectiveness of reinforcement arrangement along the horizontal direction [1].

Resins, filaments, and other additives play a crucial role in the mechanical properties of fiber-reinforced polymer (FRP) composites. In FRP composites, the filaments mainly bear normal stress, whereas the resins act to transmit the shear stress. Therefore, the rigidity and strength of FRP composites are rather large for unit mass, with desirable durability. The FRP product forms include sheets, reinforcements, and profiles. FRPs are extensively used in the bridge engineering, structural engineering, and harbor engineering [2-4]. Thus, the use of FRP as a reinforcing

*E-mail address: bcxzcx@163.com

ISSN: $1791-2377$ @ 2018 Eastern Macedonia and Thrace Institute of Technology. All rights reserved.

doi:10.25103/jestr.113.04 material in reinforced subgrades not only allows better exertion of the reinforcing effect but can also effectively improve the durability [5]. FRP-reinforced subgrades are applicable only to newly built buildings, which can, in combination with the replacement method, form an FRPreinforced cushion to achieve the purpose of ground treatment.

However, projects employing FRP materials to reinforce subgrades, as well as the application of FRP materials in the subgrades that support individual footings, are rarely reported. At present, FRP materials are only used to address the settlement of high embankments and the slope stability problem. In these cases, FRP reinforcement bars are laid in the embankment to increase the deformation modulus and bearing capacity [6]. Given that the characteristics of FRP materials differ from the conventional geosynthetics, their use as a reinforcing material to support individual footings still lacks a theoretical basis. The rationally use of FRP materials needs in-depth investigation.

The present study investigates the failure modes and reinforcement mechanisms of reinforced subgrades and examines the influencing rules of the arrangement style and number of reinforcements for the FRP materials through a laboratory model test. An optimal reinforcement arrangement scheme is proposed to attain better reinforcing effectiveness, thereby providing a reference for the design of FRP-reinforced subgrades that support individual footings.

\section{State of the art}

Many studies have focused on the strip foundations on the grounds reinforced with horizontal geosynthetics. However, 
the studies on reinforced subgrades supporting individual footings are obviously less than the strip foundations. Furthermore, the studies on vertically reinforced subgrades are distinctly fewer than those on horizontally reinforced subgrades. Yetimoglu et al. [7] studied the bearing capacity and settlement of geogrid-reinforced aeolian sands under an individual footing and provided the limit value of total reinforcement depth, the optimal reinforcement depth of the first layer, and the optimal spacing between the reinforcement layers. In this study, only the horizontal reinforcement was studied, and the arrangement style was simple. Li et al. [8-9] performed a model test on the reinforced aeolian sands under individual footing, and then proposed the bearing strength mechanism of the sand, which failed to analyze the reinforcing effectiveness. The pressure bearing capacity of foundation with reinforced aeolian sand on an individual footing was experimentally studied by Liu et al. [10]. A theoretical formula for calculating the ultimate bearing capacity of such reinforced subgrade was established, which was considered inapplicable to the vertical reinforcement. Using vertical steel wire as reinforcement, Jha and Shukla [11] experimentally researched reinforced subgrades that supported a square footing. They considered that a prominent reinforcing effect would occur when the reinforcement length was $2 b$ (b represented the footing base width) and the reinforcement range was $2 b$. Nevertheless, the applicability of their findings to the FRP materials must still be explored. Based on the failure mode and force mechanism of the horizontal-vertical reinforced soils under strip foundations, Hou et al. [12] established the ultimate bearing capacity for such subgrades. Hou considered the role and unit weight of foundation soils, footing width, number of reinforced layers, and the size of reinforcement, where the average error between the theoretical and test results was approximately $10 \%$, and the form of reinforcements was the horizontal and vertical connection. Via the field load test of the geobelt-reinforced crushed stone cushion under an individual footing, Bai et al. [13] studied the effects of the number of geobelts, the distance between first geobelt layer and footing, the vertical spacing between two geobelt layers, and the linear density of reinforcements on the mechanical properties of reinforced subgrades. Bai also compared the reinforcing effectiveness, where the reinforcement style was applicable only to the horizontal reinforcement. According to Burakbey's [14] 140 geogrid-reinforced sand laboratory model tests for cross-shaped, H-shaped, T-shaped, and square footings, the reinforcement with geogrids indicated a considerable reinforcing effectiveness, and the optimal reinforcement parameters were irrelevant to the shape of footing base. Their tests also found that the bearing capacity of reinforced subgrades could reach five times that of the unreinforced ones, where the arrangement style of reinforcements was simple. Using braided coir rope as a reinforcing material, Vinod et al. [15] studied the mechanical behavior of a square footing on reinforced loose sand. The results of their study showed that the bearing capacity of reinforced subgrade could reach six times that of unreinforced subgrade and that the ground settlement could be reduced by $90 \%$. However, the study did not discuss vertical reinforcement and other reinforcement forms. Bai's [16] research on the reinforcing properties of the grounds reinforced with FRP materials under different sizes of individual footing bases demonstrated that both the ultimate bearing capacity and the deformation modulus of the reinforced grounds decreased to a certain extent with increasing length-width ratio of the footing base. However, the influencing rules of the arrangement style and number of reinforcements were not described.

Few of the above studies investigated the arrangement style of reinforced subgrades under individual footings, especially when FRP was used as the reinforcing material. To provide the theoretical bases for the reinforced subgrades supporting individual footings and to enrich the application forms of reinforcements, we experimentally studied the FRP-reinforced subgrades that supported individual footing. Model tests of FRP-reinforced subgrades were completed in one non-reinforcement case, five horizontal reinforcement cases, and three vertical reinforcement cases that supported individual footing. The optimal reinforcement scheme was derived by comparing the ultimate bearing capacities of subgrades under different reinforcement forms, the variations of ground settlement with footing pressure, and the variations of reinforcement strains with footing pressure. Furthermore, the bearing capacity and reinforcement mechanism of FRP-reinforced subgrades were studied, all of which provided the theoretical basis for the engineering application of the FRP-reinforced subgrades.

The remainder of this study is organized as follows. Section 3 describes the device, materials, and schemes of the model tests. Section 4 analyzes the variations of footing pressure with ground settlement in the horizontal and vertical reinforcement cases, respectively, as well as the strain distributions of FRP reinforcement. The last section summarizes the study and presents relevant conclusions.

\section{Methodology}

\subsection{Test device and materials}

The model test device comprised three parts, namely, model box, loading equipment, and measuring and recording equipment, as shown in Fig. 1. The edge of the model box was welded with square steel tubes, and a $1.5 \mathrm{~cm}$-thick transparent organic glass plate was fixed on the wall of the model box. The length of the model box used for the strip foundation was modified. After modification, the length, width, and height of the box were $50.5,47$, and $60 \mathrm{~cm}$, respectively. A cubic concrete test block with a side length of $10 \mathrm{~cm}$ was used for the foundation model, whose footing size was $10 \mathrm{~cm} \times 10 \mathrm{~cm}$. Loading was performed using a jack with a measuring range of $150 \mathrm{kN}$, the applied load was measured using a pressure transducer with a measuring range of $70 \mathrm{kN}$, and the ground settlement was measured using an electronic displacement meter with a measuring range of $5 \mathrm{~cm}$.

The footing pressure-ground settlement curves were plotted based on the loads at various levels and their corresponding ground settlements, whereas the ultimate bearing capacity of subgrades and the maximum ground settlement were used to analyze the reinforcing effectiveness and to determine the optimal arrangement style of reinforcements.

The average values for the ultimate tensile strength and elastic modulus of FRP were 350 and $9589 \mathrm{MPa}$, respectively, whereas the mean elongation at rupture for FRP was $3.65 \%$. Sand material was obtained by sieving the air-dried sand. Based on the particle gradation test, the sand was identified to be the fine sand, with a uniformity coefficient of $C_{\mathrm{u}}=3.01$, and a curvature coefficient of $C_{\mathrm{u}}=0.71$. The water content of the sand was measured as $1.27 \%$, whereas its weight was $\gamma=15.6 \mathrm{kN} / \mathrm{m}^{3}$. 


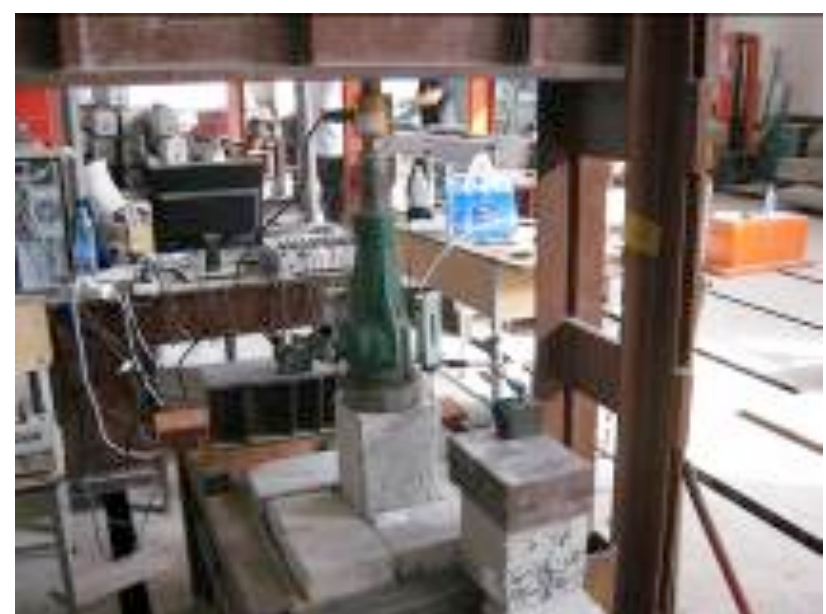

Fig.1. Experimental device

\subsection{Test schemes}

Concrete blocks were placed symmetrically around the footing, which could be converted to a preloading of 3.47 $\mathrm{kPa}$. Each case was marked with two letters, in which the first letter indicated various cases, and the second letter was used to discriminate between non-reinforcement (denoted by "n"), horizontal reinforcement (denoted by "h"), and vertical reinforcement (denoted by " $v "$ ).

The test schemes were listed in Table 1 . The size of footing base was $100 \mathrm{~mm} \times 100 \mathrm{~mm}$. To investigate the effects of reinforcement style on the reinforcing effectiveness, the test schemes were designed for a total of one non-reinforcement case, five horizontal reinforcement cases, and three vertical reinforcement cases. By monitoring the strain magnitudes and distribution patterns at various measuring points of FRP reinforcement, the reinforcing effectiveness of the reinforcement was analyzed.

Table. 1. Test schemes of reinforced subgrade

\begin{tabular}{|c|c|c|c|}
\hline No. & Case & $\begin{array}{c}\text { Reinforced or } \\
\text { not }\end{array}$ & Reinforcement conditions \\
\hline 1 & an & No & - \\
\hline 2 & bh & Yes & $\begin{array}{l}\text { Horizontal reinforcement, } \\
\text { single-layer plate }\end{array}$ \\
\hline 3 & ch & Yes & $\begin{array}{l}\text { Horizontal reinforcement, } \\
\text { double-layer plate }\end{array}$ \\
\hline 4 & dh & Yes & $\begin{array}{l}\text { Horizontal reinforcement, } \\
\text { single-layer plate with } \\
\text { peripheral inclusions }\end{array}$ \\
\hline 5 & eh & Yes & $\begin{array}{l}\text { Horizontal reinforcement, } \\
\text { single-layer plate with inner } \\
\text { and outer peripheral inclusions }\end{array}$ \\
\hline 6 & fh & Yes & $\begin{array}{l}\text { Horizontal reinforcement, } \\
\text { latticed single-layer plate }\end{array}$ \\
\hline 7 & gv & Yes & $\begin{array}{l}\text { Vertical reinforcement, four- } \\
\text { way vertical plate }\end{array}$ \\
\hline 8 & hv & Yes & $\begin{array}{l}\text { Vertical reinforcement, four- } \\
\text { way vertical plate }\end{array}$ \\
\hline 9 & jv & Yes & $\begin{array}{l}\text { Vertical reinforcement, four- } \\
\text { way vertical plate }\end{array}$ \\
\hline
\end{tabular}

(1) Horizontal reinforcement scheme

The length and width of horizontal reinforcement were 320 $\mathrm{mm}$. For cases dh and eh, the inclusions and strain gauges were located on the lower surface of the reinforcement, whereas in the remaining horizontal reinforcement cases, the strain gauges were all located on the upper surface of the reinforcement. In the case ch, the distances between upper and lower reinforcement layers and footing were 4 and $8 \mathrm{~cm}$, respectively, whereas for the rest of the horizontal reinforcement cases, the reinforcement was $4 \mathrm{~cm}$ away from the footing.

The strain gauges arranged on the reinforcements in cases bh, dh, and eh are shown in Fig. 2. The strain gauge locations of upper and lower reinforcement layers for case ch are shown in Fig. 2, in which the strain gauges for the upper layer of reinforcements are numbered 1-6, and the corresponding lower layer strain gages were numbered 7-12. The inclusions arranged on the reinforcements in cases dh and eh are shown in Fig. 3, in which the inclusions are installed only on the periphery for case $\mathrm{dh}$. The style and size of latticed reinforcements used in case fh are shown in Fig. 4(a), whereas the arrangement of strain gauges is shown in Fig. 4(b).

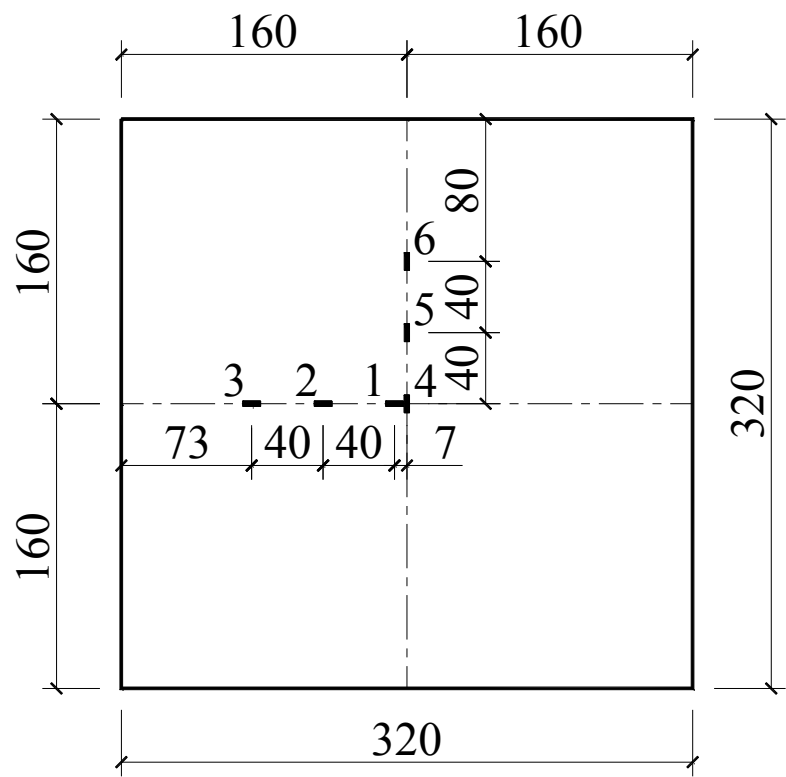

Fig. 2. Arrangement of strain gauges for cases bh, dh, and eh (in mm)

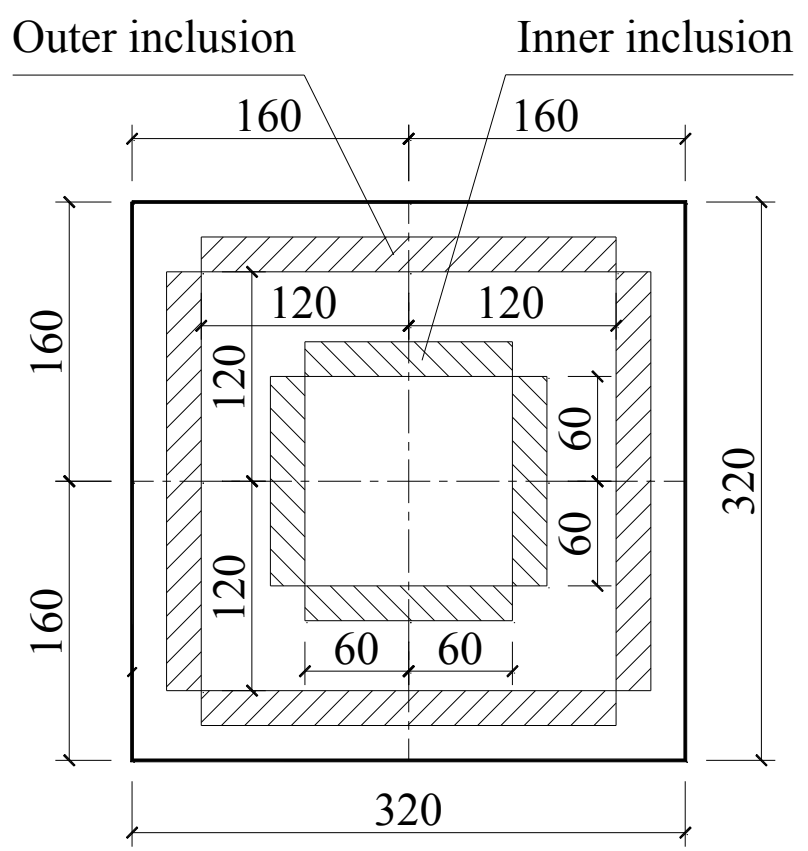

Fig. 3. Inclusions for cases $\mathrm{dh}$ and eh (in $\mathrm{mm}$ )

(2) Vertical reinforcement scheme

The reinforcement sizes and strain gauge arrangements for cases gv and jv are shown in Fig. 5(a), where the dimension 
figures before and after "/" are applicable to cases gv and jv, respectively. Figure $5(\mathrm{~b})$ shows the reinforcement sizes and strain gauge arrangements for case hv. In cases gv and jv, the upper surfaces of reinforcements were flush with the footing surfaces, whereas in case hv, the upper reinforcement surface was $2 \mathrm{~cm}$ below the foundation soil surface.
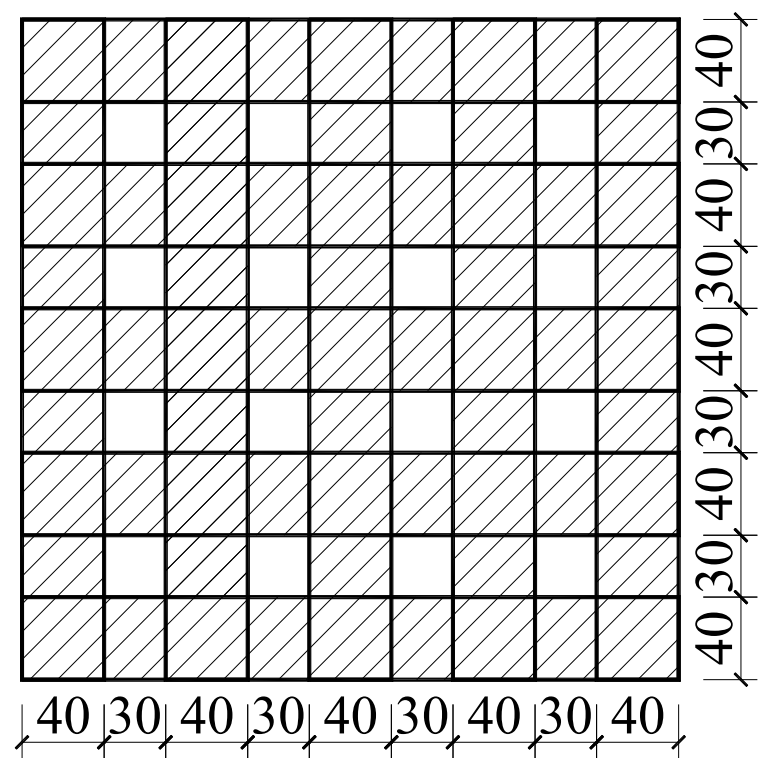

(a)

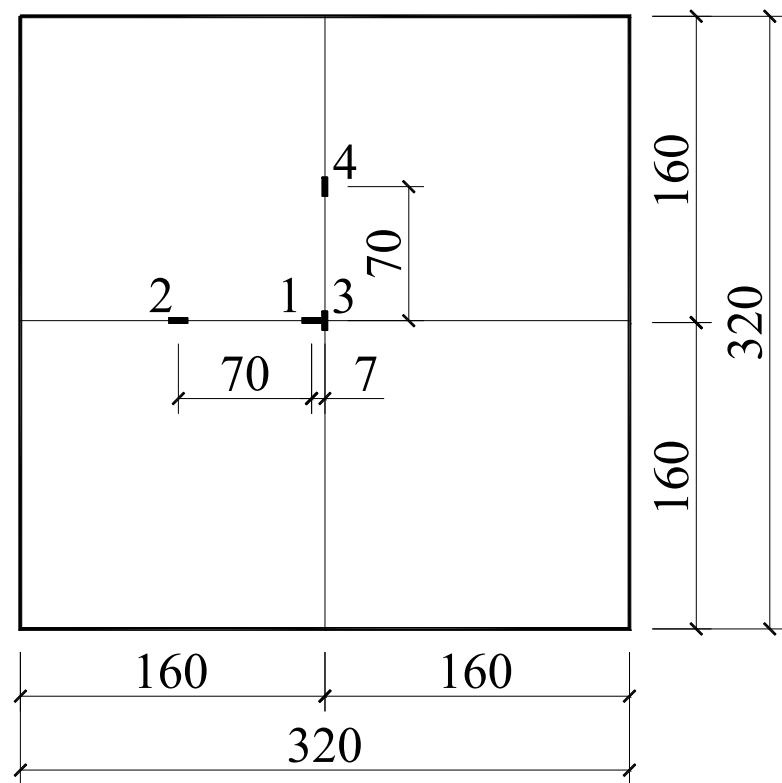

(b)

Fig.4. Reinforcement style and strain gauges for case fh (in $\mathrm{mm}$ ) (a) Reinforcement style. (b) Strain gauges

\section{Result analysis and discussion}

Tests were performed as per the schemes in Section 3. The results revealed that the shear failure of soil occurred in all cases, and for the reinforced cases, none of the reinforcements was damaged, with the presence of small plastic deformation only.

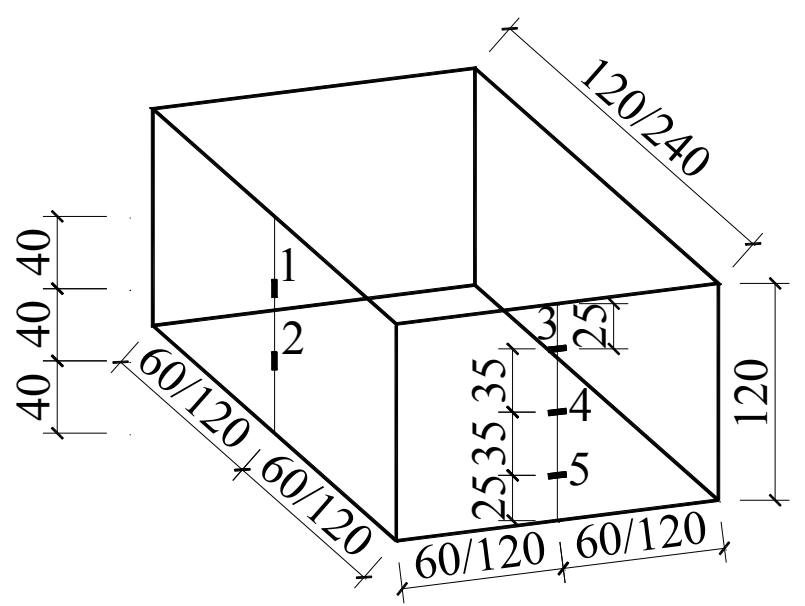

(a)

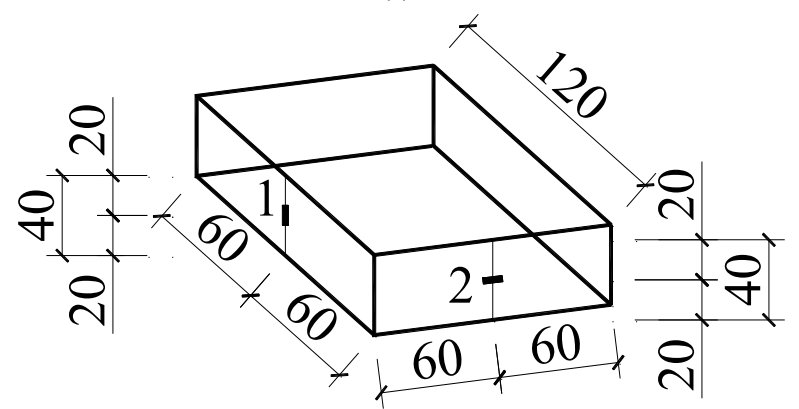

(b)

Fig. 5. Style and strain gauges for vertical reinforcement (in $\mathrm{mm}$ ) (a) Cases gv/jv. (b) Case hv

\subsection{Results and analysis of horizontal reinforcement} arrangement tests

(1) Footing pressure-ground settlement curves

Based on the results of model tests, the variations of ground settlement $\mathrm{s}$ with the footing pressure $\mathrm{p}$ could be derived, as shown in Fig. 6. In the figure, the ultimate bearing capacities of subgrades for cases an, bh, ch, dh, eh, and fh were 180.0, $520.0,1000.0,560.0,600.0$, and $480.0 \mathrm{kPa}$, respectively, whereas the corresponding ultimate ground settlements were $23.3,11.5,13.8,10.2,11.7$, and $14.6 \mathrm{~mm}$, respectively. Compared with non-reinforced case an, the ultimate bearing capacity of subgrade increased by $450 \%$, and the ultimate ground settlement decreased by $41 \%$ for the reinforced case ch, thereby attaining an excellent reinforcing effect.

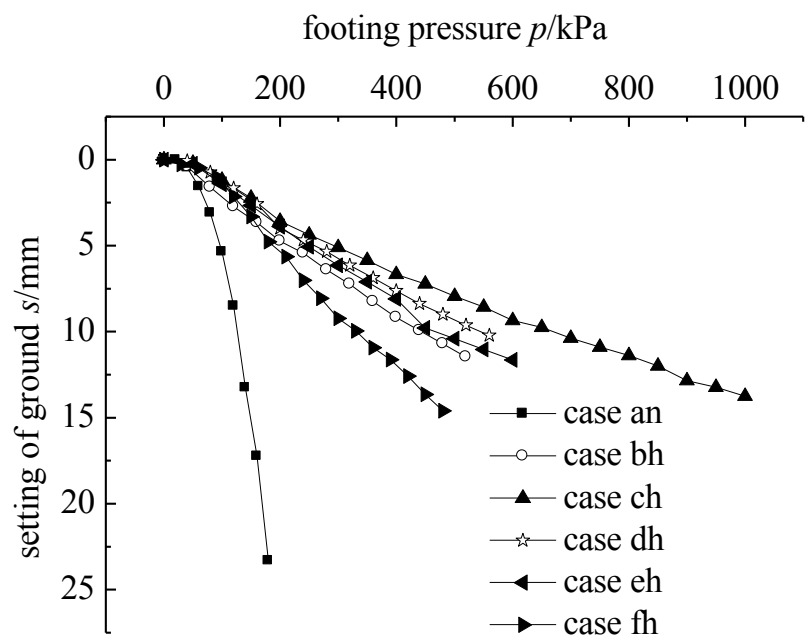

Fig. 6. Variation of footing pressure with setting of ground for horizontal reinforcement cases 
Figure 6 shows that the ultimate bearing capacity and deformation modulus of subgrade in case an were obviously lower than the reinforced cases, whereas the ultimate ground settlement was obviously larger than the reinforced cases. Compared with the single-layer plate reinforced case bh, the cases $\mathrm{dh}$ and eh with included single-layer plate reinforcement exhibited merely minor improvements in the ultimate bearing capacity and deformation modulus of subgrades, and the reinforcing effectiveness was almost the same for the three cases. These results indicated that the installation of inclusions in the present tests was undesirable for the improvement of reinforcing effectiveness. This issue requires further in-depth study. Compared with the case bh, the subgrade deformation modulus in the double-layer plate reinforced case ch did not improve remarkably, but the ultimate bearing capacity of subgrade increased considerably. Thus, the reinforcing effect of case ch was significant. As for the latticed single-layer plate reinforced case fh, the small thickness of transverse ribs led to the slightly lower ultimate bearing capacity of subgrade than the case bh. Furthermore, the deformation modulus of subgrade was also smaller than the case bh in the later loading stage.

(2) Strain distribution of FRP reinforcements

The variations of strain values at various measuring points of FRP reinforcement with the footing pressure are shown in Fig. 7. Upper and lower two layers of plates were used in the case ch. The strain distribution patterns at various measuring points of these two plates were similar to the case bh. The readings of the upper plate for case ch were greater than those the case bh, whereas the readings of lower plate were less than the case bh. The deformations of lower plate were generally smaller than the upper plate. No accurate data were acquired at measuring point 2 in case dh; thus, the data at that point were not presented in the figure. Comparison with the strain distributions at various measuring points between cases in Fig. 7 indicated that the absolute strain values for cases $\mathrm{dh}$, eh, and fh were markedly greater than the remaining cases. The strain distribution trends at various measuring points for the cases $\mathrm{dh}$ and eh were roughly similar.

\subsection{Results and analysis of vertical reinforcement arrangement tests}

(1) Footing pressure-ground settlement curves

The relationships between the ground settlement $s$ and the footing pressure $p$ in the three vertical reinforced cases and in the non-reinforced case are shown in Fig. 8. The ultimate bearing capacities of subgrades for cases an, gv, hv, and jv were $180.0,350.0,300.0$, and $650.0 \mathrm{kPa}$, respectively, whereas the corresponding ultimate ground settlements were 23.3, 22.7, 19.9, and $22.3 \mathrm{~mm}$, respectively. Compared with the non-reinforced case an, the ultimate bearing capacity of subgrade increased by $261 \%$, whereas the ultimate ground settlement decreased only by $4 \%$ in the reinforced case jv, thereby attaining a favorable reinforcing effect.

Considerable nonlinearity was observed in the footing pressure-ground settlement curve for the case an. The ultimate bearing capacity and deformation modulus of subgrades in the reinforced cases were all markedly greater than the non-reinforced case. The reinforcing effectiveness was apparently better in the case jv than the cases gv and hv, whereas the deformation modulus and ultimate bearing capacity of subgrades were identical for cases gv and hv.

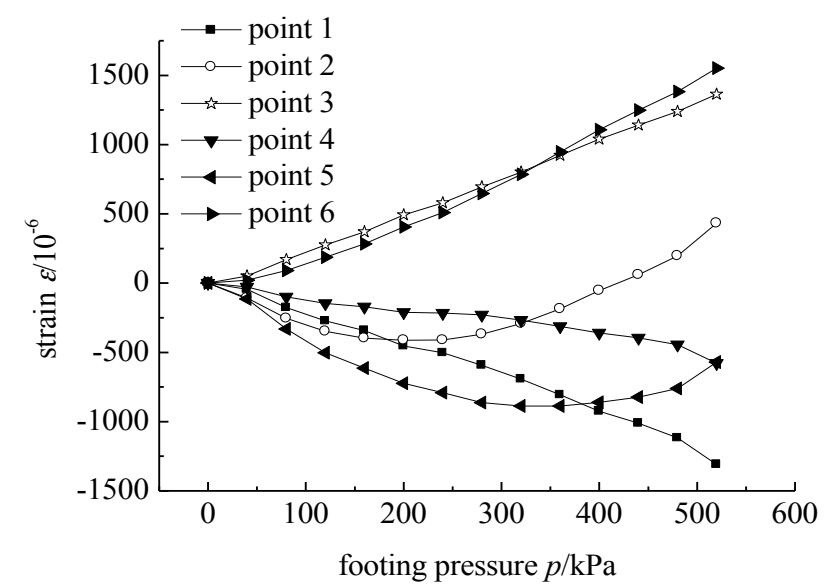

(a)

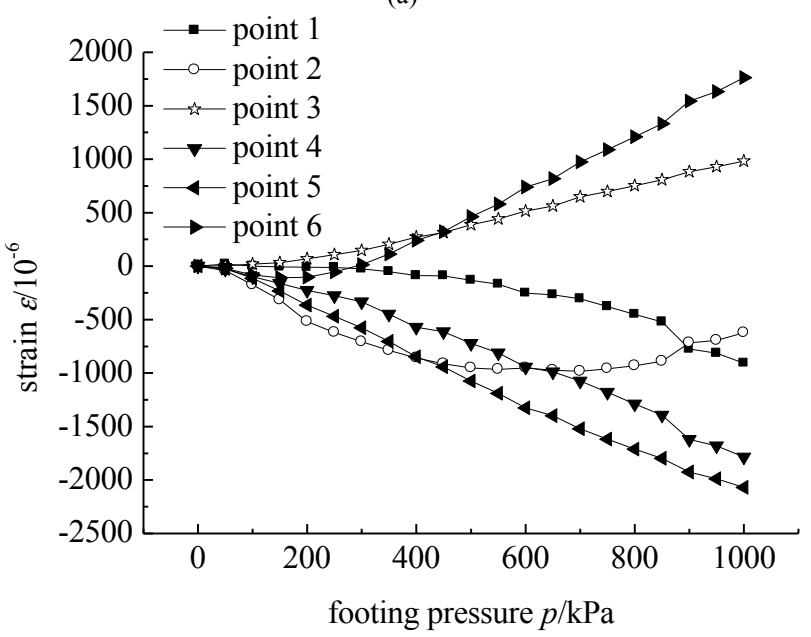

(b)

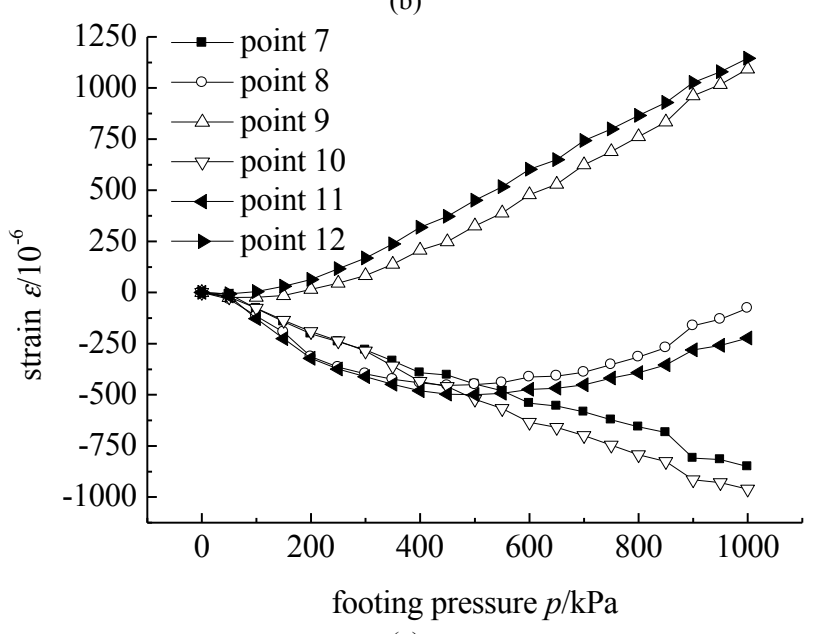

(c)

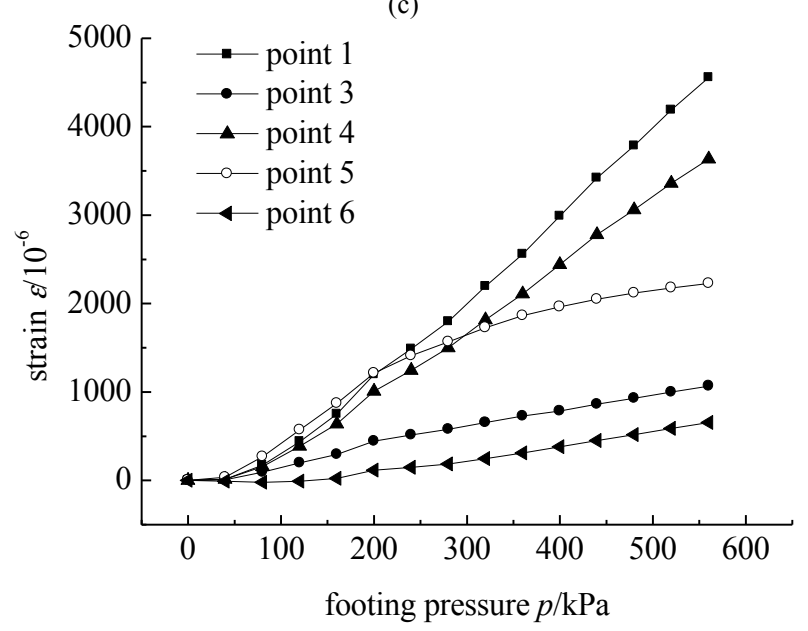


(d)

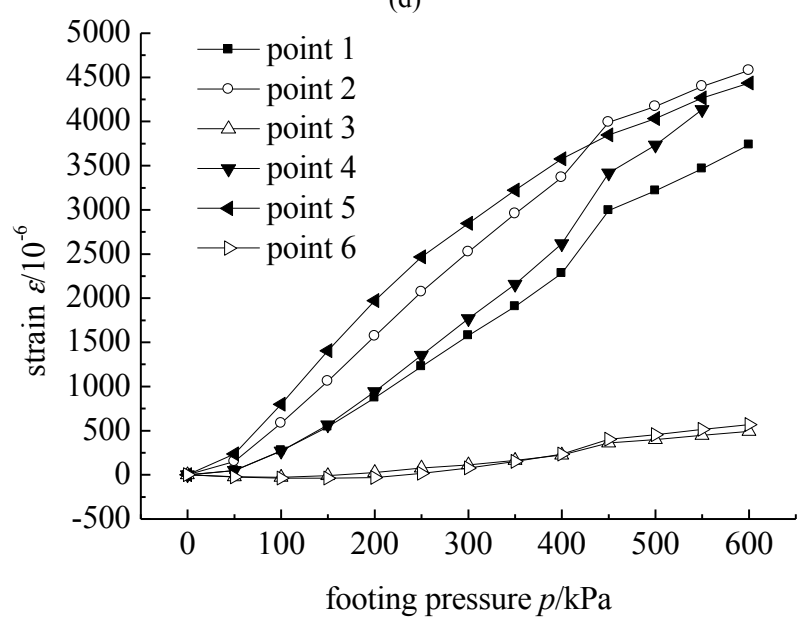

(e)

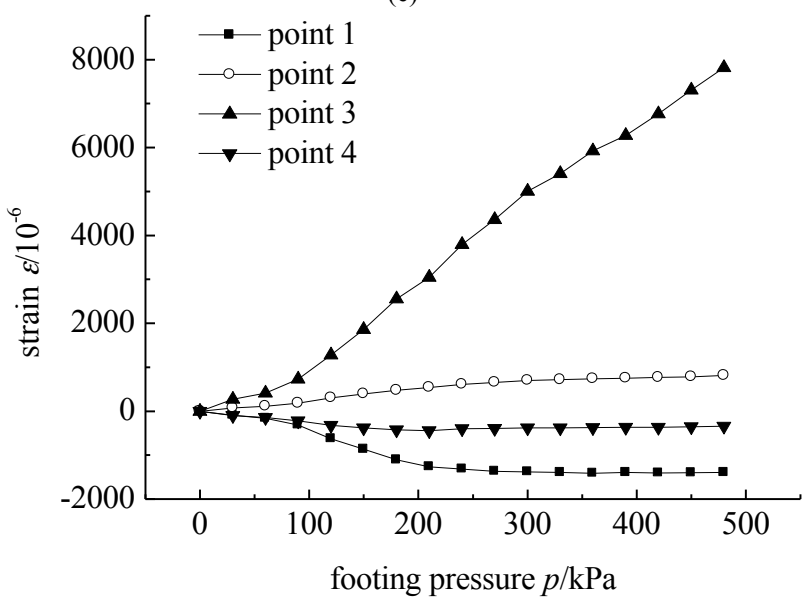

(f)

Fig. 7. Variation of footing pressure with strains of reinforcement for horizontal reinforcement cases (a) Case bh. (b) Upper reinforcement for case ch. (c) Lower reinforcement for case ch. (d) Case dh. (e) Case eh. (f) Case fh

footing pressure $p / \mathrm{kPa}$

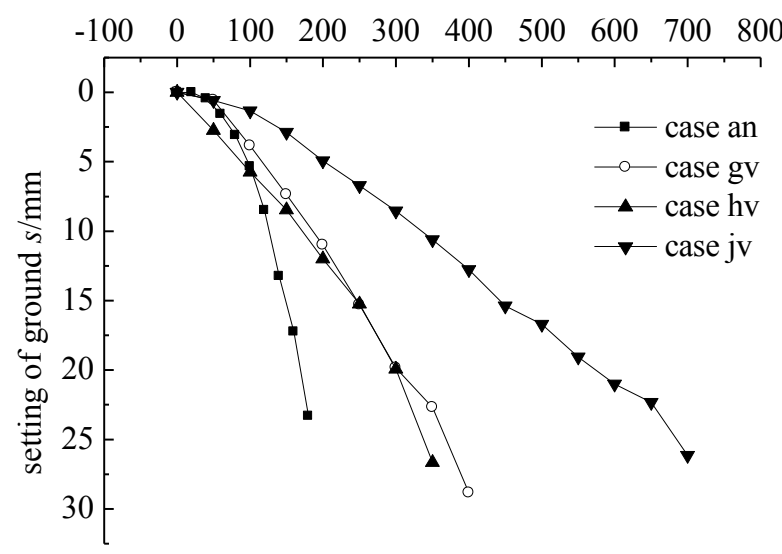

Fig. 8. Variation of footing pressure with setting of ground for vertical reinforcement cases

(2) Strain distribution of FRP reinforcements

The relationships between strain value and footing pressure at various measuring points of FRP reinforcement are shown in Fig. 9. Based on the readings of various measurement points in the case $\mathrm{gv}$, the deformation of reinforcement presented a top-down gradual decline in the vertical direction, and the reinforcement was inwardly concave in the vertical direction and outwardly convex in the horizontal direction. The uneven deformations of reinforcement in the cases hv and jv were similar to those in case gv. The magnitude of strain values indicated that the overall deformations for cases hv, jv, and gv decreased gradually, but without large gaps.

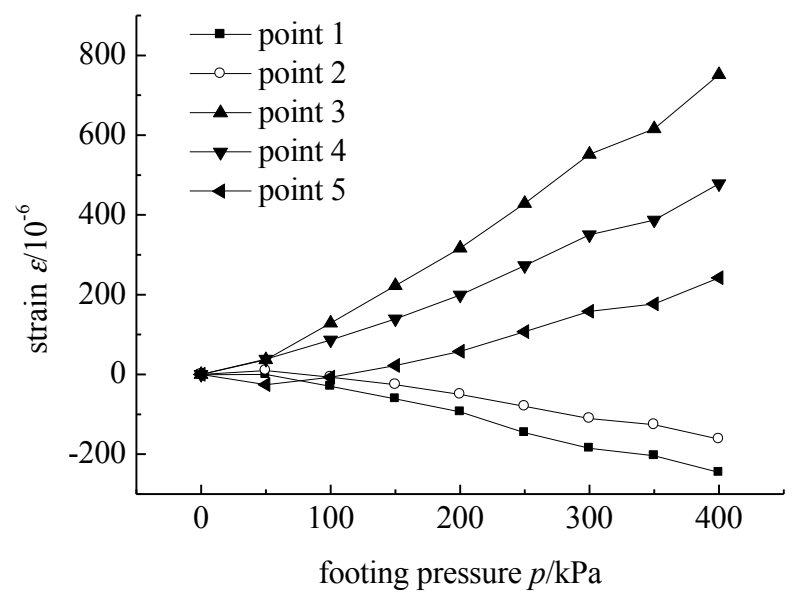

(a)

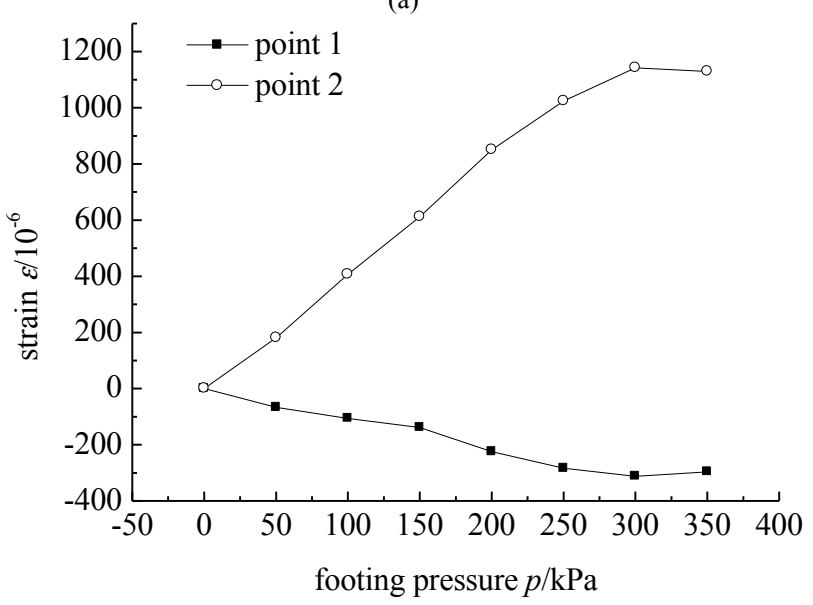

(b)

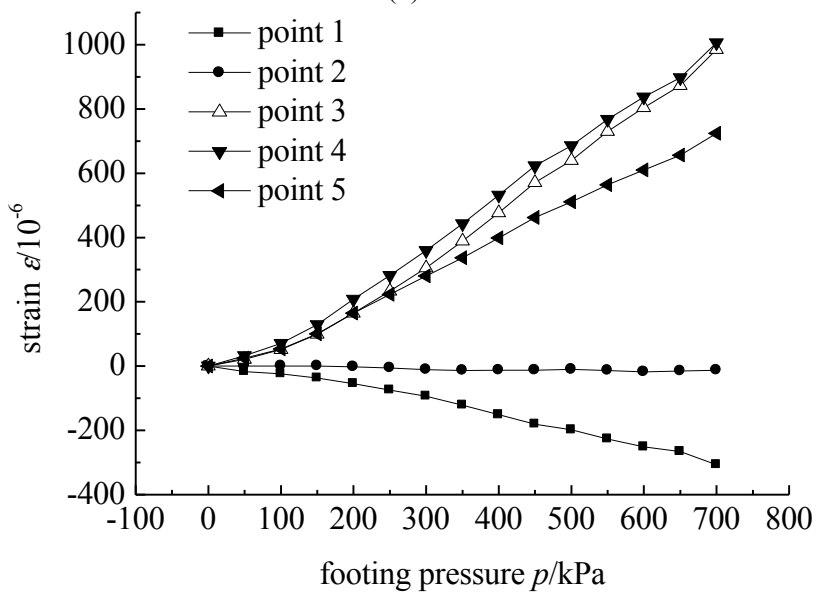

(c)

Fig. 9. Variation of footing pressure with strains of reinforcement for vertical reinforcement cases (a) Case gv. (b) Case hv. (c) Case jv

\section{Conclusions}

To reveal the reinforcement mechanisms of FRP in reinforced subgrade on an individual footing and to investigate the influencing rules of the arrangement style and 
number of reinforcements on the reinforcing effectiveness, the laboratory model test was used in this study to analyze the failure modes and reinforcement mechanisms of FRPreinforced subgrades on an individual footing. The reinforcing effectiveness was compared between various horizontal reinforcement cases, as well as between various vertical reinforcement cases. We present the below conclusions.

(1)The shear failure of soil occurs in both the nonreinforced and the reinforced cases. In addition to the widely accepted stress dispersion function of the FRP reinforcement that supports an individual footing, the vertical component of horizontal reinforcement tensile force also plays a role in supporting footing, and the vertical reinforcement plays the role of laterally constraining the foundation soil.

(2) The double-layer plate reinforcement case exhibits the optimal reinforcing effectiveness. Neither the installation of inclusions or grids plays a significant role. In the case of double-layer plate reinforcement, the deformation of the upper plate is larger than that of the lower plate. For the included reinforcement and the latticed reinforcement cases, the deformations of FRP reinforcement are greater than the other horizontal reinforcement cases.
(3) Increasing the side length and height of vertical reinforcement can both improve the reinforcing effectiveness, of which the side length increase indicates an improved effect. Regular concave-convex deformation occurs in the FRP material for all the vertical reinforcement cases, but without large deformation gaps.

The reinforcement mechanisms and effectiveness of FRP materials indicate certain practical significance for popularizing their application in the reinforced subgrades. Some numerical simulation analyses and theoretical research remain needed to develop the methods for calculating the bearing capacity and settlement of FRP-reinforced subgrades supporting individual footing.

\section{Acknowledgements}

This work was supported by the National Natural Science Foundation of China (No. 51608101), the Natural Science Foundation of Heilongjiang Province (No. E2017008), and the Heilongjiang Provincial Postdoctoral Research Funding Program (No. LBH-Q16030).

This is an Open Access article distributed under the terms of the Creative Commons Attribution Licence

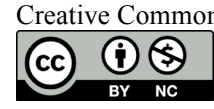

\section{References}

1. Bai C. X., Zhang Z. H., Shao X. Y., “An experimental study of strip foundation on the grounds reinforced with horizontal FRP”. Rock and Soil Mechanics, 36(4), 2015, pp.953-957.

2. Gand A. K., Chan T.-M., Mottram J. T., "Civil and structural engineering applications, recent trends, research and developments on pultruded fiber reinforced polymer closed sections: a review". Frontiers of Structural and Civil Engineering, 7(3), 2013, pp.227244.

3. Grelle S. V., Sneed L. H., "Review of anchorage systems for externally bonded FRP laminates". Internation Journal of Concrete Structures and Materials, 7(1), 2013, pp.17-33.

4. Chin S. C., Shafiq N., Nuruddin M. F., "FRP as strengthening material for reinforced concrete beams with openings - a review". KSCE Journal of Civil Engineering, 19(1), 2015, pp.213-219.

5. Bai C. X., "Tests of strip foundation on the grounds reinforced by vertical FRP”. Science Technology and Engineering, 15(5), 2015, pp.137-140, 150

6. Du Y. X., Long S. Y., Shang S P., "Static model-test study on reinforced medium-sandy embankment with prestress". Journal of Hunan University (Natural Sciences), 35(2), 2008, pp.27-30.

7. Yetimoglu T., Wu J., Saglamer A., "Bearing capacity of rectangular footings on geogrid reinforced sand". Journal of Geotechnical Engineering, ASCE, 120(12), 1994, pp.2083-2099.

8. Li C., Liu L., "Study of indoor model test of spread foundation on the reinforced aeolian sand subgrade". Chinese Journal of Geotechnical Engineering, 25(4), 2003, pp.441-444.
9. Li C., Wang J. H., "Model testing study and calculation analysis of bearing capacity on the reinforced aeolian sands ground". Chinese Journal of Rock Mechanics and Engineering, 24(4), 2005, pp.687691.

10. Liu W. B., Zhou J., Li C., Su Y. H., Liu L., "Pressure-bearing capacity of spread foundation with reinforced aeolian sand". Chinese Journal of Rock Mechanics and Engineering, 24(3), 2005, pp.537-541.

11. Jha J. N., Shukla S. K., "Bearing capacity and settlement characteristics of sand subgrades with vertical reinforcement supporting a square footing". International Journal of Geosynthetics and Ground Engineering, 2015, pp.1-16.

12. Hou J., Zhang M. X., Dai Z. H., Li J. Z., Zeng F. F., "Bearing capacity of strip foundations in horizontal-vertical reinforced soils". Geotextiles and Geomembranes, 45, 2017, pp.29-34.

13. Bai X. H., Huang X. Z., Zhang W., "Bearing capacity of square footing supported by a geobelt-reinforced crushed stone cushion on soft soil". Geosynthetics International, 20(3), 2013, pp.1-6.

14. Burakbey D., Murat O., Yakup T., "Model studies of multi-edge footings on geogrid-reinforced sand". European Journal of Environmental and Civil Engineering, 18(2), 2014, pp.190-205.

15. Vinod P., Bhaskar A. B., Sreehari S., "Behaviour of a square model footing on loose sand reinforced with braided coir rope". Geotextiles and Geomembranes, 27(6), 2009, pp.4664-474.

16. Bai C. X., Zhou Y., Shao X. Y., "Test research on the grounds reinforced with fiber-reinforced polymer material for different sizes of independent foundation bottoms". International Journal of Earth Sciences and Engineering, 8(6), 2015, pp.2860-2865. 